\title{
Existing Energy Performance and The Potential of Role of Simulation in School Building Design - A Review
}

\author{
Ming $\mathrm{Hu}$ \\ ${ }^{1}$ University of Maryland, College Park, United States
}

\begin{abstract}
The objective of this paper is to present finding of existing building performance assessment for educational buildings and related energy simulation tools with a focus on K-12 buildings. First, the paper examines the current status of energy performance in educational buildings and existing simulation tools used in building energy retrofit. Then, the paper summarizes the obstacles to conducting energy simulation for school buildings, gaps and weaknesses in existing tools will be summarized, and potential opportunities for a comprehensive tool will be outlined. Last, the paper identifies the particular needs of educational buildings, and a set of criteria and requirements for future tools will be proposed based on the particular needs for educational building.
\end{abstract}

\section{Introduction}

In the United States, educational buildings account for $12 \%$ of total commercial building energy consumption, with K-12 schools accounting for 8\% (EIA 2012). All together, educational buildings are the third largest energy consumers in the commercial building sector, following office buildings and mercantile buildings. K-12 schools account for $10 \%$ of total commercial building floor area and other educational buildings account for 4\% (EIA 2012).

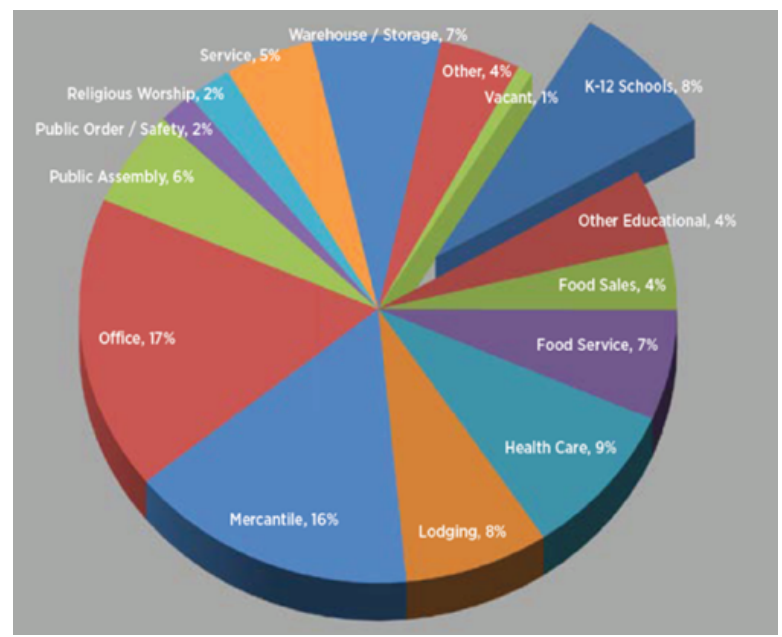

Figure 1 commercial building energy use

$\mathrm{K}-12$ school buildings in U.S spend more than $\$ 8$ billion each year on energy - more than they spend on computers and textbooks combined (EPA 2011). Most occupy older buildings that often have poor operational performancemore than $30 \%$ of schools were built before $1960.53 \%$ of public schools need to spend money on repairs, renovations, and modernization to ensure that the schools buildings are in good overall condition. And among public schools with permanent buildings, the environmental factors in these permanent buildings have been rated as unsatisfactory or very unsatisfactory in 5\% to $17 \%$ of schools (DOE 2012). The average age of a school is about 42 years - which is nearly the expected serviceable lifespan of the building (McGraw Hill 2011).

Improving the energy performance of school buildings could result in the direct benefit of reduced utility costs, and improving the indoor quality could improve the learning environment for students. Research also suggests that aging school facilities and inefficient equipment have a detrimental effect on academic performance that can be reversed when schools are upgraded. Several studies have linked better lighting, thermal comfort, and air quality to higher test scores (Chan et al, 1979; Earthman et al. 1998; Phillips et al. 1997). Another benefit of improving the energy efficiency of education buildings is the potential increase in market value through recognition of green building practice and labelling such as that of a net zero energy building. In addition, because of their educational function, high-performance or energy-efficient buildings are particularly valuable for institution clients and local government. More and more high-performance buildings, net zero energy buildings, and positive energy buildings serve as living laboratories for educational purposes. Currently, educational/institutional buildings represent the largest portion of NZE (Net Zero Energy) projects. Educational buildings comprise $36 \%$ of all net zero buildings, according to a 2014 National New Building Institute report. Of the 58 net zero energy educational buildings, 32 are used for kindergarten through 12th grade (K-12), 21 for higher education, and five for general education (NBI 2014).

\section{Existing Energy Performance Of K-12 Building}

For this study, first author compared three different database: Building Performance Database, EIA's (Energy Information Administration) Commercial Building Energy Consumption Survey (CBECS), and Building Energy Data Book. BPD was chosen because of its size and non-biased sources. BPD is the United States largest dataset of information about the energy-related characteristics of commercial and residential buildings. 
This database is sponsored by Department of Energy and raw data come from variety sources includes federal, state and local government data, as well as utility companies and other energy efficiency programs. In BPD, there are 8883 school buildings. In the CBECS, there are 389 education buildings include elementary, middle school, high school, college and other types of adult education and vocational training facilities. CBECS is much smaller dataset than BPD. Building Energy Data Book does not list the original raw data quantity, so it is hard evaluating its' reliability.

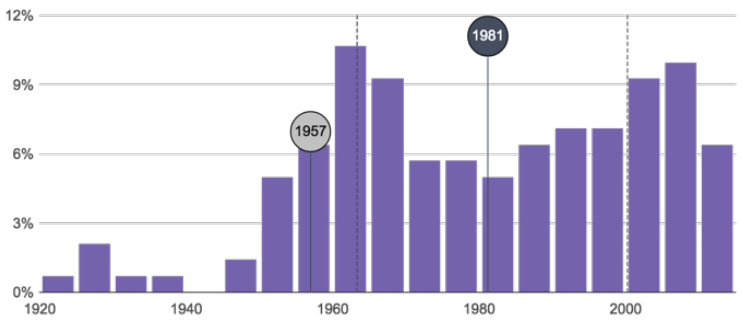

Figure 2 Age of school buildings in U.S.

The energy performance of $\mathrm{K}-12$ buildings is primarily affected by three impact factors: site/climate condition; building total area; and very significantly by occupancy rate. The first impact factor in education building energy performance is the external environment conditions. In the U.S., based on BPD data there is a clear correlation between cold climate zone and overall energy consumption. Buildings in hot climate zone have better performance than those in cold climate, as illustrated in Figure 3. From data obtained in Europe, studies also indicated that the energy usage intensity (EUI) is typically higher in regions with a harsh and cold climate than in those with relatively pleasant climate conditions.

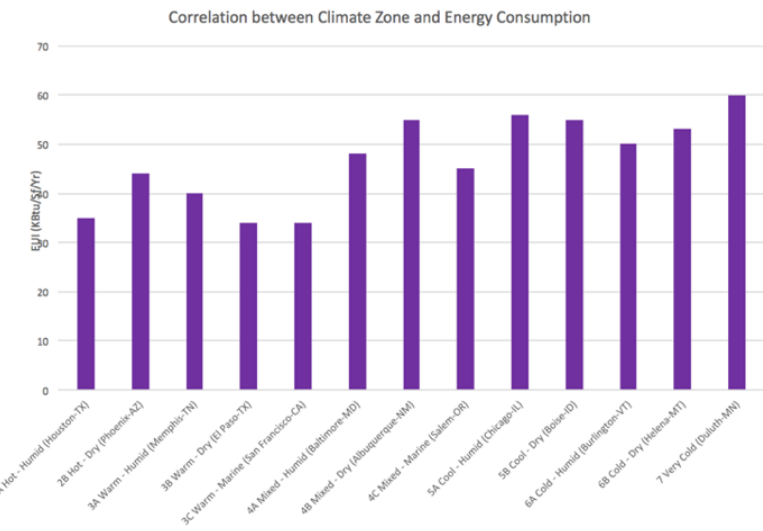

Figure 3 Correlation between climate zone and energy efficiency

The second factor is the overall area of the buildings. First, author has ruled out the impact from construction year. Building ages is not the key issue affecting the energy performance, the newer buildings particularly built around 1990s to 2000s have higher EUI number than those built before 1980s. This could due to the larger plug load in newer schools. When we look at the building total area, smaller buildings tend to have higher energy intensity compared to larger building which is the same across different climate zones and building ages.
The third factor is occupancy rate. Data shows lower occupancy density is correlated to the higher EUI, which suggest fewer people consume more energy due to the behavior change. This could be interpreted by the occupant's behaviors. In the United States, historically low energy prices have contributed to building occupants engaging in relatively energy-intensive behaviors (Climate Policy Initiative Report 2013). In other countries due to the conscious mind of energy conservation, we have seen close correlation between building operational characteristic of the buildings as a result of how they affect the actions taken by students or teachers to control their internal environment (Theodosiou et al 2014).

\section{Existing Simulation Tools Used In Building Energy Analysis}

Realizing the energy efficient design is a two-steps concept: first is to reduce energy consumption, and the second is to increase the energy generated on site through renewable energy. The different steps require different simulation tools. The first set of tools (energy consumption simulation tool) is utilized to predict the future energy consumption based on sufficient parameters with the aim to make sure the energy demand could be reduced to minimal. This type of tool has been in development since the past 50 years, and typically requires experienced professionals from the building community. The second set of tools (energy generation simulation tool) is used to predict the energy generated onsite, which could depend on the site and geographic condition. Most tools also require certain professional training and knowledge in the utilization of these tools. More and more whole building simulation software is starting to include the potential energy generation on-site combined with predicted energy consumption on-site so that the design team can view the energy balance result in one interface.

In energy consumption simulation tools, the core tools in the building energy efficiency field are the wholebuilding energy simulation programs. Those programs can take a large number of building parameters into consideration such as building geometry, massing, orientation, wall-window ratio, temperature, humidity, energy use and demand, and costs. Large bodies of research and surveys have been conducted to compare different energy simulation tools. Among those surveys and studies, two research projects have the most impact. In 2006, a team of research from U.S DOE and Scotland studied twenty major building energy consumption simulation programs and concluded that even among the 'mature' tools, there was not a common language to describe what the tools could do, and solely relying on a single tool might not be productive (Crawley et al 2008). In 2010, researchers from Ireland and Denmark studied 37 tools in collaboration with the tool developers or recommended points of contact. This study provides a review of different computer tools that can be used to analyse the integration of renewable energy generation (Connolly et al 2010). Among the 37 tools studied, four programs are applicable to single-building, group of buildings, or a community. Those four programs are 
BCHP Screening Tool, HOMER, and TRNSYS16. Between those two studies, there is only one overlap (Trnsys16). In this session, the author chose 10 of the most used and most invested whole-building simulation programs and illustrated their characteristics based on a high number of users from the previous studies.

\section{Gaps And Potential Opportunities For Educational Building Energy Simulation}

Currently, most whole-building simulation tools generally focus on commercial and residential buildings. According to the most recent Commercial Building Energy Consumption Survey (CBECS), conducted in 2012, space heating demanded the greatest overall energy use $(25 \%)$, followed by lighting, refrigeration, ventilation, and cooling. In residential buildings, space heating demanded the greatest overall energy use $(45 \%)$, followed by water heating $(18 \%)$ and space cooling $(9 \%)$. School buildings have a unique energy profile that does not align with that of typical commercial buildings. In school buildings, space heating accounts for $47 \%$ of the overall energy consumption, followed by lighting (14\%) and cooling $(10 \%)$. The energy behavior of schools is more similar to that of a residential building than that of a commercial building. This could be due to the operational schedule of schools; in particular, primary and secondary schools are largely different from regular commercial buildings that operate on a 12 months per year schedule. Further research could be conducted to obtain a better understanding of school building energy behavior. Using a typical commercial energy simulation model setting for school buildings could create inaccurate results. There is a potential gap and need for integrated simulation tools that are created and suitable for school building design. In most existing schools, the building system does not have smart sensors that can automatically control the lighting, so one can often observe that sun shades and blinds are pulled down during the day to avoid glare while the electric lights are all turned on because of the reduced daylight level. Hence, the users' energy behavior management requires a cultural shift, which could take a long time, and we should simulate the energy consumption caused by the relatively high-intensity energy behavior in schools. A future energy simulation tool should accommodate a wide range of operation schedules and users' behavior could lead to more accurate results. Illustrating the direct savings from behavior change could create a positive environment to expedite the behavior paradigm shift.

\section{Conclusion}

Educational buildings in the U.S. consume large amounts of energy, representing immense opportunities for energy savings. K-12 schools offer unique opportunities for deep, cost-effective energy-efficiency improvements. According to the EPA, the modification of a pre-existing school building for energy efficiency can save a typical 100,000 -square-foot school building between $\$ 10,000$ and $\$ 16,000$ annually. Future building performance will not be generic and will vary according to the buildings' operational character, local context, and user behaviors. The overall goal of future buildings, including educational buildings, may be "net zero" or "net positive". The intent of reviewing the current energy performance status of K-12 buildings is to and identifying the gaps and opportunities for improvement of K-12 building performance.

\section{References}

Energy Information Administration (2012). Commercial Building Energy Survey.

Environment Protection Agency (2011). Energy Efficiency Programs in K-12 Schools: A Guide to Developing and Implementing Greenhouse Gas Reduction Programs.

Department of Education (2012) U.S. Condition of America's Public School Facilities.

Schneider, Mar (2002). Do School Facilities Affect Academic Outcomes? National Clearinghouse for Educational Facilities.

Chan, T (1979). The impact of school building age on pupil achievement. Greenville, S.C.: Office of School Facilities Planning, Greenville School District.

Earthman, G. I., and L. Lemasters (1998). Where children learn: A discussion of how a facility affects learning. Paper presented at the annual meeting of Virginia Educational Facility Planners. Blacksburg, Va.

Phillips, R. (1997). Educational facility age and the academic achievement of upper elementary school students. Unpublished doctoral dissertation. University of Georgia.

Cortese, A., Higgins, C., \& Hewitt, D. (2014). Getting to Zero Status Update: A Look at the Projects, Policies, and Programs Driving Zero Net Energy Performance in Commercial Buildings. Vancouver, WA: New Buildings Institute, 4, 21.

Initiative, C. P., Amecke, H., Deason, J., Hobbs, A., Novikova, A., Xiu, Y., \& Shengyuan, Z. (2013). Buildings Energy Efficiency in China, Germany, and the United States.

Theodosiou, T. G., \& Ordoumpozanis, K. T. (2008). Energy, comfort and indoor air quality in nursery and elementary school buildings in the cold climatic zone of Greece. Energy and Buildings, 40(12), 2207-2214.

Crawley, D. B., Hand, J. W., Kummert, M., \& Griffith, B. T. (2008). Contrasting the capabilities of building energy performance simulation programs. Building and environment, 43(4), 661-673.

Connolly, D., Lund, H., Mathiesen, B. V., \& Leahy, M. (2010). A review of computer tools for analysing the integration of renewable energy into various energy systems. Applied energy, 87(4), 1059-108

Oak Ridge National Laboratory. Whole-Building and Community Integration Program. $<$ http://www.coolingheatingpower.org/about/bchpscreening-tool. php $>$ [accessed 26.05.09]. 
Connolly, D., Lund, H., Mathiesen, B. V., \& Leahy, M. (2009). Developing a model of the Irish energysystem. Proceedings of the Joint Action on Climate Change. Aalborg.

Murray, M., Finlayson, N., Kummert, M., \& Macbeth, J. (2009, July). Live energy TRNSYS-TRNSYS simulation within google SketchUp. In Eleventh International IBPSA Conference, Glasgow, Scotland. pp1389-1396.
Efficiency, E. (2011). Energy Efficiency Programs in K12 Schools.

Deng, S., Dai, Y. J., Wang, R. Z., \& Zhai, X. Q. (2011). Case study of green energy system design for a multifunction building in campus. Sustainable Cities and Society, 1(3), 152-163 